\title{
TRISOMY 21 WITH A SMALL SUPERNUMERARY MARKER CHROMOSOME DERIVED FROM CHROMOSOMES 13/21 AND 18
}

Niksic SB ${ }^{1}$, Deretic VI ${ }^{2}$, Pilic GR ${ }^{1}$, Ewers E ${ }^{3}$, Merkas $\mathrm{M}^{3}$, Ziegler $\mathrm{M}^{3}$, Liehr T,*

*Corresponding Author: Thomas Liehr, Institut für Humangenetik, Postfach, D-07740 Jena, Germany; Tel.: +49-3641-935-533; Fax: +49-3641-935-582; E-mail: i8lith@mti.uni-jena.de

\begin{abstract}
We describe a trisomy 21 with a small supernumerary marker chromosome (sSMC) derived from chromosomes 13/21 and 18 in which the karyotype was $48, \mathrm{XY},+\operatorname{der}(13$ or 21$) \mathrm{t}(13$ or $21 ; 18)(13$ or $21 \mathrm{pter} \rightarrow 13 \mathrm{q} 11$ or $21 \mathrm{q} 11.1:: 18 \mathrm{p}$ $11.21 \rightarrow 18$ pter $),+21$. Of the 35 case reports in the literature for a karyotype $48, \mathrm{XN},+21,+$ mar, in only 12 was the origin of the SSMC determined by fluorescence in situ hybridization (FISH), and only one was a $\operatorname{der}(13$ or 21$)$ and none were derived from two chromosomes. The influence of the partial trisomy $18 p$ on the clinical outcome was hard to determine, however, there are reports on clinically healthy subjects for partial trisomy $18 \mathrm{p}$.
\end{abstract}

Key words: small supernumerary marker chromosome (sSMC), Partial trisomy 18p, Down syndrome

Background. Down syndrome (DS) is caused by trisomy of human chromosome 21 and occurs in about $0.45 \%$ of human conceptuses. The incidence is

1 Institute of Mental Health, Department of Medical Genetics, Belgrade, Serbia

2 University Children's Hospital, Belgrade, Serbia

3 Jena University Hospital, Institute of Human Genetics and Anthropology, Jena, Germany influenced by maternal age and affected fetuses are at an increased risk of miscarriage [1]. Different theories are discussed how free trisomy 21 develops during maternal meiosis $[2,3]$. In 35 reported DS cases instead of a karyotype $47, \mathrm{XN},+21$ there was a karyotype $48, \mathrm{XN},+21,+$ mar, i.e., a small supernumerary marker chromosome (sSMC) was also present [4]. The sSMC are a morphologically heterogeneous group of structurally abnormal chromosomes which may represent different types of inverted duplicated chromosomes, minute chromosomes and ring chromosomes. They can be characterized unambiguously by molecular cytogenetics and are usually equal in size or smaller than a chromosome 20 in the same metaphase spread. They can also be present in: 1) a karyotype of 46 normal chromosomes, 2) a numerically abnormal karyotype (such as DS) or 3) a structurally abnormal but balanced karyotype (e.g., Robertsonian translocation) or ring chromosome formation [5]. About $10 \%$ of sSMC are complex rearranged, i.e., they consist of more than one chromosomal region. Some $85 \%$ of this subgroup are present in Emanuel or der(22) syndrome with a karyotype 47,XN,+der(22)t(11;22)(q23;q11) [4]. The remainder may arise from any human chromosome and have different genetic contents $[4,6]$. Here we report on a unique case of trisomy 21 with an SSMC derived from chromosomes 13/21 and 18 . 


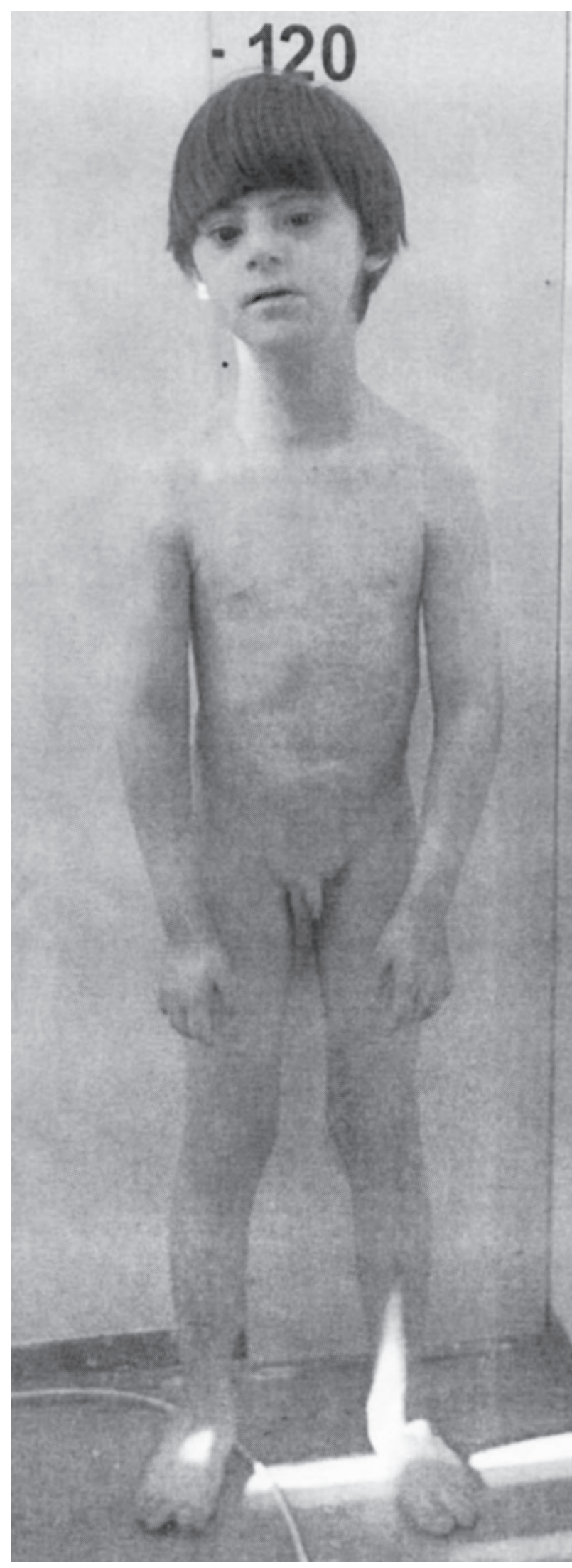

Figure 1 Photograph of the patient at 6 years of age.
Case Presentation. Characteristic clinical signs of DS were already present at birth, like the specific facial appearance (see Figure 1). He had a very pronounced retardation of motor development and only started to walk when he was 6 years old. He was moderately mentally retarded, had low body weight and an elongated neck, resembling his mother in the latter two characteristics.

Chromosomal analysis revealed a karyotype of $48, \mathrm{XY},+21,+$ mar in all analyzed cells. The karyotype of the parents was normal. Application of multiplex fluorescence in situ hybridization (M-FISH) [7] confirmed the presence of three chromosomes 21, one of which contained material from chromosome 18 and possibly from chromosome 21 (Figure 2A). Application of commercially available subtelomeric probes for chromosome 18 (Abbott, Wiesbaden, Germany) and a centromeric probe specific for chromosomes 13 and 21 (Kreatech Diagnostics, Amsterdam, The Netherlands) revealed p-arm material of chromosome 18 on the sSMC, which was derived from chromosome 13 or 21 (Figure 2B). The presence of three DS critical regions but not on the sSMC was demonstrated by an appropriate commercial probe (LSI 21; Abbott). By subcentromere-specific M-FISH [8] using specific probe sets for chromosomes 13, 18 and 21 (Figures 2D-2F) the final karyotype was determined as $48, \mathrm{XY},+\operatorname{der}(13$ or 21$) \mathrm{t}(13$ or $21 ; 18)(13$ or $21 \mathrm{pter} \rightarrow 13 \mathrm{q} 11$ or $21 \mathrm{q} 11.1:: 18 \mathrm{p} 11.21 \rightarrow 18 \mathrm{pter}),+21$. The chromosomal origin of the sSMC could not be determined more exactly because of sequence identity of the centromeric regions of chromosomes 13 and 21.

\section{DISCUSSION}

The presence of 48 chromosomes in DS is a rare finding. It can be caused by an additional gonosome leading, e.g., to a karyotype $48, \mathrm{XXX},+21[9,10]$ or by an sSMC [4]. Up to now, for sSMC derived from chromosomes 4, 7, 13 (two cases), 14, 14/22, 15 (two cases) and 22 (three case) have been reported in DS [4]. Ours is the first report of an sSMC in DS derived from chromosome 13 or 21 and the first complex rearrangement of one.

Among the complex rearranged of sSMC, chromosome $13 / 21$ is the second most frequently involved [6]. An sSMC like the one we describe 


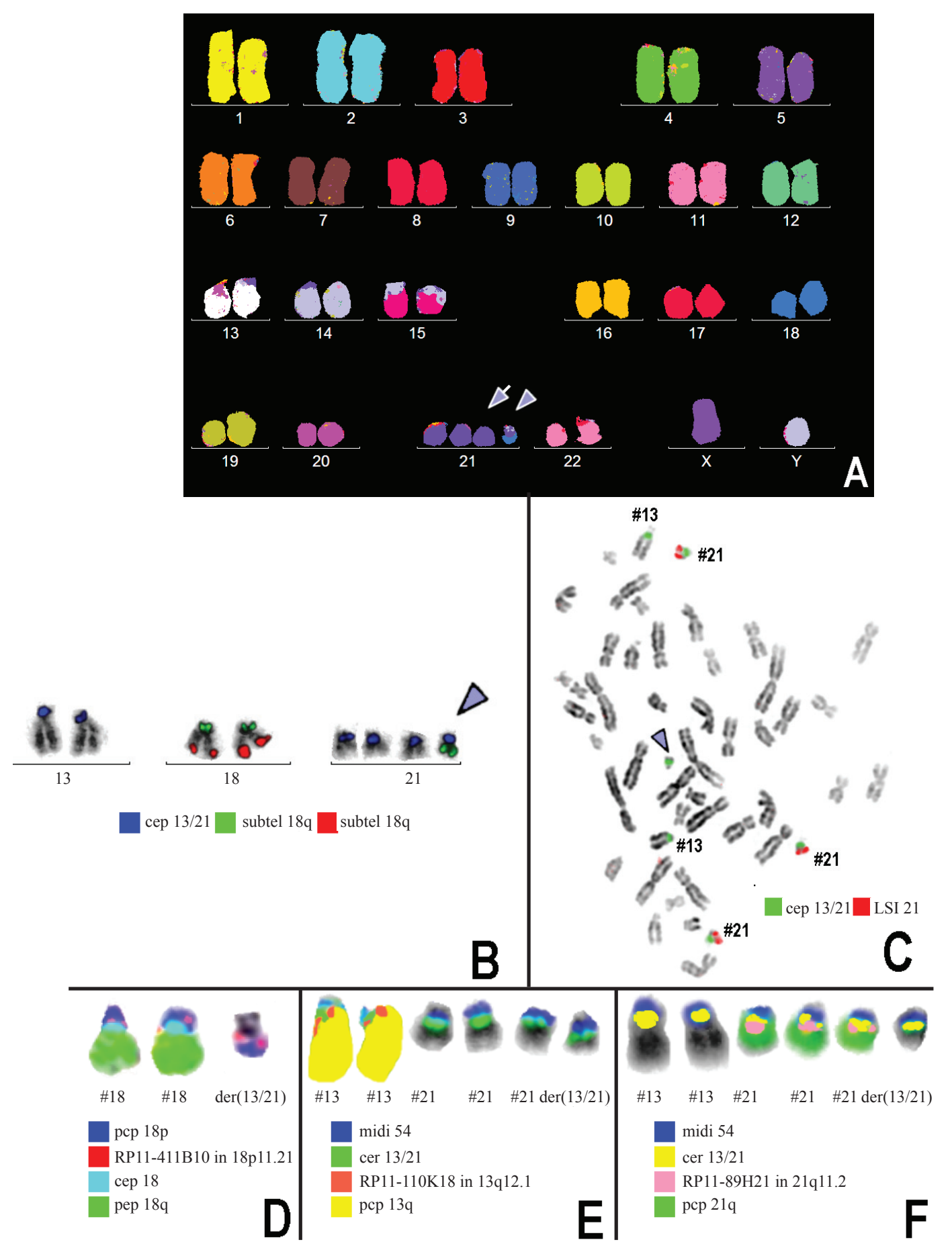

Figure 2 The FISH results obtained on the chromosomes of the reported patient. A) The M-FISH showed trisomy 21 (arrow) and an sSMC (arrowhead). B) Subtelomeric probes for chromosome 18 (subtel 18p and subtel 18q) and for the centromeric regions of chromosomes 13 and 21 (cep 13/21). Note the short arm material derived from chromosome 18 present on the sSMC. C) Down syndrome critical region (LSI 21) was present in the three chromosomes 21 but not on the sSMC (arrowhead). Abbreviation: cep 13/21: centromeric probe specific for chromosomes 13 and 21. D-F) SubcenM-FISH for the chromosomes 18, 13 and 21. Note the short arm of chromosome 18 present on the sSMC but not the centromeric region of that chromosome. Locusspecific centromere-near probes for chromosomes 13 and 21 did not detect euchromatic sequences on the sSMC. Abbreviations: cep $=$ centromeric probe; midi $54=$ probe specific for the short arms of all acrocentric chromosomes [14]; pcp = partial chromosome paint. 
here, leading to partial trisomy $18 \mathrm{p}$ was reported in five individuals $[6,9-11]$ in four of which no, or only minor malformations and/or mental impairment, were found $[6,11,12]$, in the fifth, no postnatal data were available, but sonography gave normal results [13]. Apart from the pronounced retardation in motor development, we observed no obvious influence of partial trisomy $18 \mathrm{p}$ in our patient. This suggests that some genes present on $18 \mathrm{p}$ cause severe problems when present as four copies, as in $\mathrm{i}(18 \mathrm{p})$-syndrome [5], but not when present as three copies.

Competing Interests. The author(s) declare that they have no competing interests.

\section{ACKNOWLEDGMENTS}

This study was supported in part by the DFG (LI 820/22-1) and DAAD (D07/00070). Drs. Snezana B. Niksic and Gordana R. Pilic performed the cytogenetic studies in the present case, Dr. Vesna I. Deretic provided genetic counseling to the parents, performed cytogenetic studies in the parents and collected the clinical data relative to this case report, Drs. Elizabeth Ewers, Martina Merkas, Monika Ziegler and Thomas Liehr performed the molecular cytogenetic analysis and interpretation. Dr. Thomas Liehr drafted the report and all authors contributed to the finalizing of the manuscript. Written consent was obtained from the parents for publication of this case report.

\section{REFERENCES}

1. Wiseman FK, Alford KA, Tybulewicz VL, Fisher EM. Down syndrome-recent progress and future prospects. Hum Mol Genet 2009; 18(R1): R75-R83.

2. Hultén MA, Patel SD, Tankimanova M, Westgren M, Papadogiannakis N, Jonsson AM, Iwarsson E. On the origin of trisomy 21 Down syndrome. Mol Cytogenet 2008; 1: 21.

3. Migliore L, Migheli F, Coppedè F. Susceptibility to aneuploidy in young mothers of Down syndrome children. TheScientificWorldJournal 2009; 9: 1052-1060 (see http:// thescientificworld. co.uk/headeradmin/upload/2009.06. 122.pdf).

4. Liehr T, Claussen U, Starke H. Small supernumerary marker chromosomes (sSMC) in humans. Cytogenet Genome Res 2004; 107(1-2): 55-67.
5. Liehr T. Small supernumerary marker chromosome homepage. http://www.med.unijena.de/fish/sSMC/ 00START.htm. accessed on 7 November 2009.

6. Trifonov V, Fluri S, Binkert F, Nandini A, Anderson J, Rodriguez L, Gross M, Kosyakova N, Mkrtchyan H, Ewers E, Reich D, Weise A, Liehr T. Complex rearranged small supernumerary marker chromosomes (sSMC), three new cases; evidence for an underestimated entity? Mol Cytogenet 2008; $1: 6$.

7. Liehr T, Starke H, Weise A, Lehrer H, Claussen U. Multicolor FISH probe sets and their applications. Histol Histopathol 2004; 19(1): 229-237.

8. Starke H, Nietzel A, Weise A, Heller A, Mrasek K, Belitz B, Kelbova C, Volleth M, Albrecht B, Mitulla B, Trappe R, Bartels I, Adolph S, Dufke A, Singer S, Stumm M, Wegner RD, Seidel J, Schmidt A, Kuechler A, Schreyer I, Claussen U, von Eggeling F, Liehr T. Small supernumerary marker chromosomes (SMCs): genotype-phenotype correlation and classification. Hum Genet 2003; 114(1): 51-67.

9. Jeanty C, Turner C. Prenatal diagnosis of double aneuploidy, 48,XXY,+21, and review of the literature. J Ultrasound Med 2009; 28(5): 673-681.

10. Kovaleva NV, Mutton DE. Epidemiology of double aneuploidies involving chromosome 21 and the sex chromosomes. Am J Med Genet A 2005; 134A(1): 24-32.

11. Mabboux P, Brisset S, Aboura A, Pineau D, Koubi V, Joannidis S, Labrune P, Tachdjian G. Pure and complete trisomy $18 \mathrm{p}$ due to a supernumerary marker chromosome associated with moderate mental retardation. Am J Med Genet A 2007; 143A(7): $727-$ 733.

12. Rodriguez L, Liehr T, Mrasek K, Mansilla E, Martinez-Fernandez ML, Garcia A, MartinezFrias ML. Small supernumerary chromosome marker generating complete and pure trisomy $18 p$, characterized by molecular cytogenetic techniques and review. Am J Med Genet A 2007; 143A(22): 2727-2732.

13. Minelli E, Müller-Navia J, Mazzola D, Mny P, Bronz L, Uhr M. Characterization of a marker chromosome with FISH and microdissection in prenatal diagnosis. Ann Genet 2003; 46(1): 325.

14. Mrasek K, Heller A, Rubtsov N, Trifonov V, Starke H, Claussen U, Liehr T. Detailed Hylobates lar karyotype defined by 25-color FISH and multicolor banding. Int J Mol Med 2003; 12(2): 139-146. 